\title{
Hacia la historia del Movimiento Estudiantil en Colombia: elementos teórico-metodológicos fundamentales
}

\author{
Daniel Yepes Grisales* \\ (danielyepesgrisales@gmail.com)
}

\author{
Victor Santiago Calle León ${ }^{* *}$ \\ (estorvicalle@yahoo.es)
}

Articulo corto recibido el 27/11/2014 y aprobado el 19/12/2014

\begin{abstract}
Cómo citar este artículo:
YEPES GRISALES, Daniel y Victor Santiago Calle León (2014). "Hacia la historia del Movimiento Estudiantil en Colombia: elementos teórico-metodológicos fundamentales”. En: Trans-pasando Fronteras, núm. 6, pp. 217-240. Cali, Colombia: Centro de Estudios Interdisciplinarios, Jurídicos, Sociales y Humanistas (CIES), Facultad de Derecho y Ciencias sociales, Universidad Icesi.
\end{abstract}

\begin{abstract}
Resumen
El presente ensayo responde a la pregunta sobre cómo abordar el estudio de la historia del Movimiento Estudiantil en Colombia desde las disciplinas Ciencia Política, Historiografía Política o Sociología Política. Inicialmente se detiene en justificar la pertinencia del propósito mismo de historizar dicho objeto (el ME colombiano), es decir, la necesidad de la pregunta. Como respuesta a la misma se alude a la necesidad de emprender esfuerzos descriptivos como primer paso para la comprensión de nuestro objeto de estudio, en el marco más general de la historia política colombiana como contexto interpretativo ulterior. En un segundo momento expositivo se argumenta la pertinencia de abordar el objeto Movimiento Estudiantil mediante las teorías de la acción colectiva y, particularmente, de los movimientos
\end{abstract}

* $\quad$ Estudiante de Ciencia Política de la Universidad de Antioquia, Colombia.

** Estudiante de Ciencia Política de la Universidad de Antioquia, Colombia. 
sociales. Una vez establecida dicha necesidad, se desarrollan algunas discusiones con Charles Tilly con el propósito de producir un concepto claro y operativo de movimientos sociales -diferenciándolo de movilización de masas- que pueda servir a los investigadores colombianos de los movimientos sociales y particularmente del ME. Finalmente se exponen las categorías descriptivas fundamentales en que se descompone el concepto producido de movimiento social. Estas categorías se las desprende de su origen estadounidense y, a modo de ejemplo sugerente, se desarrolla y operacionaliza una de ellas (estructura organizativa). A modo de conclusión, se expone una síntesis del contenido del ensayo y se declara el propósito de contribuir a la promoción de iniciativas académicas sobre movimientos sociales, como parte de una historia política colombiana desde el punto de vista analítico de los subalternos, propósito ineludible de todo científico social colombiano comprometido con nuestras realidades históricas y políticas.

\section{Palabras clave:}

Movimiento estudiantil, historia política de Colombia, historiografía descriptiva, movimientos sociales, Ciencia Política.

\section{Introducción}

El supuesto generalmente aceptado con el que partimos es que el año 2011 marca un giro en la trayectoria de la protesta estudiantil en Colombia. En el mes de marzo, cuando el Gobierno Nacional presentó a la opinión pública la propuesta de reforma a la Ley de Educación Superior (ley 30), los estudiantes de todo el país, convocados por organizaciones estudiantiles a un encuentro nacional en Bogotá, deciden crear la Mesa Amplia Nacional Estudiantil (MANE), organización representativa y unitaria que recuerda los precedentes de la Federación de Estudiantes de Colombia (FEC) creada tras las protestas que terminaron en la tragedia de 1954, ${ }^{1}$ la Federación de Estudiantes Universitarios (FUN) de los sesenta y la Coordinadora Nacional de Estudiantes Universitarios (CNEU) de comienzos de la década del 2000.

A lo largo de 2011, particularmente en el segundo semestre, la movilización social estudiantil impulsada y liderada por la MANE demostró la potencial relevancia política del Movimiento Estudiantil (en adelante ME) por su magnitud, amplitud, convocatoria,

1 El 8 y 9 de junio resultan muertos varios estudiantes. Desde entonces, dichas fechas se conmemoran anualmente como Día del Estudiante Caído o Combativo. En algunas de esas conmemoraciones han resultado nuevos heridos y muertos. Para mayor información: http://somosnuestramemoria.blogspot.com/2011/06/documentossobre-el-8-y-9-de-junio-dias.html 
duración, continuidad, innovación, impacto y eficacia, planteando problemas e interrogantes por igual a los gobernantes y a los estudiosos de lo social, particularmente a los politólogos, quienes, hasta ahora, poco se han interesado en los movimientos sociales y menos aún en el ME. ${ }^{2}$

Adriana González, investigadora del Instituto de Estudios Políticos de la Universidad de Antioquia, avizoraba con asombrosa claridad tales preguntas para la investigación social y política en septiembre de 2010, recordando que el proceso renovador de la política por parte del Movimiento Estudiantil -que en 2011 llegaría a un importante pico-no era tan nuevo, sino un proceso histórico que venía de años atrás:

De este modo, entre anacronismos denunciados -en los discursos y en la acción-, miedos instalados -en la memoria y en la experiencia cotidiana-, y un contexto de cambios en las coordenadas de la acción colectiva, irrumpieron actores y formas inéditas de actuación y se configuraron nuevos espacios, planteando desafios políticos pero también retos importantes a la investigación en materia de movimientos sociales y acción colectiva (2010: 28).

Mauricio Archila, uno de los estudiosos de los movimientos sociales en Colombia, hablando propiamente sobre el ciclo de 2011, corrobora la mencionada relevancia política y su carácter novedoso, de lo cual se desprenden claramente las consecuencias para la investigación académica, pues según él dicho ciclo puso de relieve la legitimidad de los movimientos sociales como forma de hacer política.

Si bien el ciclo de la lucha estudiantil en Colombia no ha terminado, ya ha dejado algunas lecciones que es bueno resaltar: la renovación del repertorio de protesta con acciones lúdicas y simbólicas, la combinación de las acciones institucionales y no institucionales, la convergencia de estudiantes de instituciones públicas y privadas así como de los de secundaria, la posibilidad de acción unitaria por parte de diversas corrientes políticas juveniles y estudiantiles, la participación de profesores y padres de familia; y, sobre todo, la capacidad de convocar a la sociedad en su apoyo. Es cierto que el foco del conflicto es educativo, pero a nuestro juicio, los estudiantes no lo abordan en forma particu-

2 Para una excelente reseña de la campaña de protesta de 2011, construida por estudiantes, véase: https:// es.wikipedia.org/wiki/Movilizaci\%C3\%B3n_estudiantil_en_Colombia_de_2011 
larista sino como un derecho que involucra, no sólo a los actuales estudiantes, sino a toda la sociedad. En ese sentido ha sido una acción política renovadora en cuanto a la forma y el contenido, que muestra la legitimidad de la protesta callejera como una manera de producir cambios en la sociedad (2012: 95).

El mismo autor concluye sobre este punto: "Todavía es temprano para decir si 2011 será un año de quiebre en la historia del Movimiento Estudiantil colombiano, pero sin duda será un año memorable" (2012:96). Afirmación que nos lleva justo al centro de nuestra pesquisa puesto que, en efecto, habría que preguntarnos: ¿cómo saber si 2011 es un año de quiebre en la historia del ME cuando no existe su historia escrita de carácter completo y suficiente, y por tanto no son claros los parámetros en que se fundamentaría un juicio sobre la coyuntura reciente?

\section{Historiografía política descriptiva del Movimiento Estudiantil}

Suponemos que hubo movilizaciones estudiantiles que por su impacto merecen ser recordadas y sin embargo permanecen en las sombras del olvido o, a lo sumo, se conservan en la memoria de sus protagonistas como meros relatos personales. Habría que suponer que el lector de este texto podría no recordar algunos de los acontecimientos que han sido descritos, y que quienes lo escriben seguramente no han recordado otros ocurridos en el mismo período, y declaradamente no recordamos muchos otros de períodos anteriores, no a causa de la tautología de no haberlos presenciado, sino porque la memoria no es algo que exista o no exista, que se genere automática y espontáneamente, sino que es construcción colectiva, es un proceso: el proceso de hacer memoria.

Adriana González puede orientarnos en este asunto, puesto que en su propuesta es evidente la conexión que establece entre lo social y lo político, a la vez que entre política e historia en el estudio de los movimientos sociales:

tras la continuidad en las expresiones de protesta se ve reflejada la persistencia de conflictos políticos y sociales en el marco de nuevas condiciones y pese a los cambios favorables operados. Se trata en este caso de la recuperación de una memoria y una experiencia colectiva portadora de aprendizajes previos, cuya pérdida ha venido soslayando la dimensión histórica y política de la protesta. En tiempos en que la invocación a la memoria 
parece un imperativo necesario para conducir esta sociedad hacia la restitución de los derechos de las víctimas y para garantizar la no repetición de atropellos cometidos en nombre de un orden, parece apenas moralmente correcto no hacer tabla rasa de las contribuciones al proceso inacabado y perfectible de nuestra democracia que hicieron generaciones anteriores de luchadores populares, activistas e intelectuales de la protesta, a quienes sin duda las vicisitudes de la movilización los interrogaron también sobre las formas, oportunidad y pertinencia de acciones que parecieron eventualmente condenadas al fracaso (2010: 27).

Es ese un primer propósito de nuestro ejercicio, contribuir a la memoria histórica del Movimiento Estudiantil, de expresiones sociales y políticas que han contribuido de una u otra manera -contribución que configura en sí otra pregunta-a los avances, retrocesos, ires y venires de los proyectos de nación colombiana. Y para que sigan contribuyendo, porque, como dice el colectivo Antígona en un artículo titulado Sobre el Movimiento Estudiantil actual y su historia, "la memoria del Movimiento Estudiantil debe servir para construir procesos de movilización. Debemos construir procesos estudiantiles de movilización desde estas memorias de las luchas. 'La memoria salva, escoge, filtra, pero no mata. La memoria y el deseo saben que no hay presente vivo con pasado muerto, ni habrá futuro sin ambos'. Carlos Fuentes" (Antígona, 2011).

Empero, pretendemos llegar a algo más que la mera recuperación de la "memoria de los hechos", dado que nuestra intervención es en el campo de la Ciencia Política. Un reto mayor nos espera luego de ese "hilar" -lineal y cronológico- los hechos representativos de la memoria histórica por construirse, se trata justamente de la comprensión de esos hechos, de su carácter, de sus elementos causales múltiples y complejos, de su relación e incidencia bidireccional entre ellos y con otros acontecimientos y movimientos sociales. En últimas, de lo que se trata es de interpretar el papel que ha jugado el Movimiento Estudiantil en la historia política de Colombia y en cada una de las coyunturas políticas en las que ha hecho su presencia.

De ahí que demarquemos el espectro temporal de nuestros estudios desde el año 1957, año en el que, con la caída del general Rojas Pinilla (a la cual contribuyó el Movimiento Estudiantil) y la instauración del Frente Nacional, se inicia en Colombia la llamada crisis de representación de los partidos, en la cual se diluyen las identidades partidistas liberal 
y conservadora, fundiéndose, como afirma Mauricio Arrubla, en "una misma finalidad estratégica, que era la de mantener un orden institucional general en el que se combinaran el esquema político democrático y el esquema económico capitalista" (1978: 206).

Por lo mismo, los movimientos sociales a partir de esa fecha comenzarían a tener mayor relevancia política, apoyados principalmente por las fuerzas de izquierda excluidas del pacto frentenacionalista, a tal punto que, como nos dice el mismo autor, "el escenario de la lucha, de otra parte, ha tendido a ubicarse en zonas de cierto modo periféricas, como el monte y la universidad" (Arrubla, 1978:211), y va más allá al demostrar la importancia de dicho año, pues a partir de entonces "la generalidad de las organizaciones inspiradas en el marxismo y promotoras de un cambio en el sentido del socialismo pueden ser consideradas como grupos estudiantiles tanto por el origen inmediato de sus cuadros de dirección como por la composición de su militancia. Universidad e inconformismo político han llegado a identificarse" (Arrubla, 1978: 211).

Sin embargo, a ese objetivo de interpretación global de las coyunturas no podremos llegar con el presente trabajo, puesto que aquel requeriría de todo un programa de investigaciones para realizarse. No obstante, se intentará abordar un objetivo que contribuye a avanzar en dicho programa. Se trata de un conocimiento descriptivo profundo de los elementos estructurantes del Movimiento Estudiantil durante las campañas o ciclos más importantes que se identifiquen en el periodo de casi seis décadas señalado.

Conocimiento descriptivo que nos permita comprender toda la complejidad contenida en la pregunta por el Movimiento Estudiantil, permitiéndonos responder cuál ha sido su composición orgánica, cuáles sus repertorios tradicionales y propios, cuáles sus marcos simbólicos, culturales e identitarios, sus formas de concebirse a sí mismos, sus reivindicaciones y sus adversarios.

\section{Sobre el método y la metodología para el estudio del Movimiento Estudiantil}

Para dichas indagaciones iniciales se debería adoptar la perspectiva fenomenológica,la cual podríamos sintetizar como la actitud filosófica orientada a "tratar de describir la experiencia sin recurrir a explicaciones causales" (Holstein y Gubrium, 1994). Algunos autores, estudiosos de los movimientos sociales, han argumentado a favor de esta perspectiva descriptiva que proponemos: 
Nuestros más cuidadosos taxonomistas de las estructuras de movilización no dejan de advertirnos que antes de intentar explicar sus causas y consecuencias debemos proceder a clasificarlas. Sus reservas parecen provenir de la difundida tendencia entre los estudiosos de movimientos sociales a desarrollar explicaciones complejas sobre el surgimiento de las formas de estos movimientos sin haberlas delimitado previamente ni empírica ni conceptualmente (...). Hace casi tres décadas que Neil Smelser, tras luchar por intentar dotar de sentido a la acción colectiva, dijo: 'Aunque la delimitación de las formas de acción colectiva no constituya un fin en sí mismo ni sea tan interesante como la investigación dirigida a averiguar las causas y consecuencias de las conductas colectivas, resulta de vital importancia. Antes de poder plantear cuestión alguna debemos ser conscientes del carácter que revisten los fenómenos que queremos explicar (Smelser, 1963)'. (Mcadam, Mccarthy, y Zald, 1999: 207)

La perspectiva fenomenológica nos induce a una modalidad cualitativa de investigación, dado que ésta presenta mayor riqueza y profundidad descriptiva de fenómenos que en sí son de carácter cualitativo, aun cuando pudiera intentarse cuantificarlos, puesto que en este momento investigativo nuestro interés no se encuentra en medir impactos o magnitudes, sino en describir cualidades y características del fenómeno en cuestión.

La estrategia metodológica especializada que más se corresponde con este ejercicio investigativo es el estudio de caso, entendiéndolo como aquél que "investiga un fenómeno contemporáneo dentro de su contexto real de existencia, cuando los límites entre el fenómeno y el contexto no son claramente evidentes y en los cuales existen múltiples fuentes de evidencia que pueden usarse" (Yin, 1993:23).

Sin embargo, junto con la metodología del estudio de caso, se deberá implementar, como método, la historiografía política, con lo cual se presenta una mixtura o híbrido que nos parece indispensable: se trata del estudio de un caso en perspectiva histórica. Cuando decimos que es importante el estudio del objeto Movimiento Estudiantil, con ello aún no se ha dicho cómo debería estudiarse. Como se sabe, esta cuestión metodológica está estrechamente ligada con la cuestión más profunda del método, la cual remite a su vez al campo de los enfoques teóricos disciplinares y, en últimas, al paradigma epistemológico desde el que se aborda la construcción disciplinar de los objetos políticos. Aquí el debate entre la Historia, la Sociología y la Ciencia Política cobra toda su importancia. 
Dentro de ésta última se suele hablar, como modalidades de investigación más usuales y aceptadas, de los estudios de caso, los análisis comparados, la historia política y el análisis de coyuntura política. Pero los casos a estudiar -y comparar- pueden abordarse en perspectiva sincrónica o diacrónica, histórica o ahistórica, dinámica o estática, y a su vez una coyuntura se puede tomar como ruptura, como discontinuidad o como corte, y la historia política puede abordarse como lineal, escalonada, por saltos o periodizada por totalidades históricas. Aquí es evidente que las discusiones teóricas propias de la historia como disciplina adquieren relevancia para la Ciencia Política.

A su vez, dentro de las modalidades de investigación politológica aceptadas, suelen presentarse enfoques que relacionan de forma diversa el objeto político en cuestión con otros objetos sociales, o en otros términos, que presentan de forma distinta la relación entre la sociedad y la política, y con ello entre la Sociología y la Ciencia Política: o bien los objetos políticos se enmarcan y se ven determinados por un contexto social, o por el contrario sus determinaciones y lógicas son intrínsecamente políticas.

Nuestra postura es que no es posible comprender un fenómeno político si no es en perspectiva histórica, de ahí que consideremos las disciplinas Historia y Ciencia Política íntimamente ligadas. Pero además, dicha perspectiva histórica está lejos de bastarse por sí misma en su aplicación a "los casos", es decir, no consideramos posible hacer historias (interpretación histórica) particulares de cualquier fenómeno político, porque los fenómenos políticos los consideramos enmarcados y determinados por el contexto social en el que surgen y en el que a su vez intervienen activamente. Así pues, si bien consideramos que lo político posee una autonomía relativa que permite fundamentar la legitimidad de la disciplina politológica, está ligado a su vez a la sociedad de la que emerge (Althusser, 1965).

En términos de lo avanzado sobre la relación con la Historia, el estudio histórico de lo político está en relación insoslayable con el estudio histórico de los demás niveles o instancias de lo social. Para nuestro caso: la historia política de Colombia (objeto de estudio holístico de la Ciencia Política colombiana) debe inscribirse en la historia de la sociedad colombiana, la historia de Colombia como formación social (Althusser, 1965).

A su vez, la historia política -y sus coyunturas- se descompone en múltiples procesos que implican diversos actores, procesos que vienen a llamarse propiamente los casos de estudio. El ME constituye pues un caso de estudio para la Ciencia Política, pero no 
existe una historia propiamente dicha (interpretativa) de tal fenómeno, porque la historia política de Colombia -objeto histórico real- lo incluye y lo desborda.

El ME es nuestro caso de estudio. Tal caso sólo podrá ser comprendido (reiteramos que nuestro objetivo actual aún no es de alcance comprensivo, sino descriptivo) en relación, primero con el ME en las diferentes ciudades de Colombia, y segundo con otros movimientos y fenómenos políticos locales y nacionales. Tales serían los pasos a seguir en un posible programa de investigación en Ciencia Política. Pero para la construcción de la historia política de Colombia, como relación entre procesos y fenómenos políticos particulares, primero hay que conocer la historiografía particular (descriptiva) de dichos procesos particulares, una de las cuales es la que aquí pretendemos apuntalar.

La perspectiva fenomenológica, sin embargo, no la concebimos como total o final. En efecto, el presente trabajo hace parte de un programa de investigación que en proyectos subsiguientes abordará empresas comparativas enmarcadas en las modalidades de análisis de coyuntura e historia política -estructural-, desde una perspectiva interpretativa con las bases teóricas del Materialismo Histórico. Así pues, la fenomenología la adoptamos como perspectiva provisional, durante el proceso de construcción de las nociones -conocimiento descriptivo- de nuestro objeto, las materias primas de posteriores esfuerzos investigativos. ${ }^{3}$

Finalmente, la especificidad politológica de la investigación es demandada por el hecho mismo de que la historiografía política del Movimiento Estudiantil, al abordarse en perspectiva fenomenológica, requiere de herramientas teóricas acordes a la labor descriptiva. Esas herramientas conceptuales las tomamos de las teorías de la Acción colectiva y los Movimientos sociales, particularmente de la escuela de la Contienda Política. Esto tiene una razón histórica, además de teórica, que pasaremos a exponer.

\section{Arsenal conceptual para el estudio del Movimiento Estudiantil: Acción colectiva y}

\section{Movimientos sociales}

El abordaje conceptual del Movimiento Estudiantil ha sido objeto de discusiones enconadas y eternas, tanto desde los ámbitos de la academia, como desde espacios no

3 Deberán consultarse los textos suplementarios referidos en la nota 2 para mayor información sobre la perspectiva teórica y metodológica del programa de investigaciones. 
institucionales de producción teórica y finalmente desde los mismos ámbitos estudiantiles y las organizaciones políticas con intereses allí. ${ }^{4}$

Si bien la historia de las protestas estudiantiles podría remontarse a la historia misma de la universidad -al menos de la forma histórica de universidad propia de la sociedad de masas-, es a partir de los acontecimientos sociales y políticos acaecidos en diversos lugares del mundo entre 1967 y $1971^{5}$, protagonizados por el Estudiantado, que comienzan las grandes discusiones en torno a su comprensión y particularmente en torno a su conceptualización.

El "mayo parisino" - considerado el caso emblemático y representativo- se podría abordar como una rebelión estudiantil, una revolución cultural, un ciclo de protesta, un movimiento social, una insurrección, un estado de anarquía, entre otros. No obstante dicha diversidad, en casi todas las formas en que ha sido abordado, se ha resaltado el hecho de haber contenido un alto grado de novedad (Riechmann, 1994).

Esa novedad, en el caso de la tradición académica del estudio de la acción colectiva (AC) y de los movimientos sociales (MS), se tradujo, por una parte, en la manifiesta caducidad de las teorías del comportamiento colectivo para explicar éste tipo de fenómenos evidentemente racionales, abanderados por una fracción "ilustrada" de la sociedad.

Por otro lado, a raíz del mayo parisino se comenzó a hablar en las ciencias sociales de un cambio social estructural producto del 68 -o cuya expresión era el 68-, al punto en que empiezan a aparecer nociones como nuevos movimientos sociales (NMS), crisis de los partidos, crisis social de representación, con lo cual se comienza a dar desde la academia mayor relevancia, tanto a los aspectos contextuales de la $\mathrm{AC}$, como también y especialmente a sus aspectos culturales (Riechmann, 1994).

Como vemos, el punto neurálgico de las discusiones sobre el ME coincide con el punto neurálgico de las discusiones sobre la AC en general. Mayo del 68 se concibe así como un hito que marca una ruptura, tanto en la historia de la movilización estudiantil y en la AC en general, como en las ciencias sociales. Es por ello que aparece

4 Para una reseña de este debate en Colombia deberán consultarse los textos referidos en la nota 2.

5 EEUU, Alemania Oeste, España, Inglaterra, Checoslovaquia e Italia (1967), Francia, China, Japón y México (1968), Pakistán y Colombia (1971), entre otros (Navia, 1999). 
como pertinente el abordaje académico del ME a partir de las herramientas conceptuales aportadas por la acción colectiva y las teorías de los movimientos sociales, en cuyo ámbito de discusiones será necesario ubicarnos.

"Movimientos sociales" (MS) ha sido una expresión usada incontables veces para designar fenómenos sociales y políticos diversos, realmente existentes y perceptibles a la vista de todos, pero que pocas veces sabemos a qué refiere, cuales son los elementos que harían o no a un fenómeno un Movimiento Social.

Así, a menudo en este campo de estudios nos encontramos en un estado primitivo en el que, para entender de lo que hablamos, a falta de conceptos, recurrimos a señalar con el dedo: movimientos sociales son el ecologista, el estudiantil, el feminista, el obrero, el campesino, y así sucesivamente, siempre referidos a tal o cual país, aunque de algunos, también señalados con el dedo, a veces se dice que son trasnacionales o por el contrario de corte local o subnacional.

Los intentos más juiciosos de conceptualizar de forma positiva, en su especificidad, los MS, se han concentrado en autores anglosajones, especialmente estadounidenses. Allí hemos reconocido dos vertientes teóricas gruesas en el ámbito de la definición: los que tienden a considerarlo un grupo humano empírico que, a través de la distribución de incentivos selectivos, se organiza para luchar por la atribución de un bien público (Olson, 2011) y los que lo consideran más como una forma particular entre las formas modernas de hacer política entendida como acción contenciosa (Tilly, 1995).

Ambas vertientes incluyen al fenómeno en el más amplio de la Acción Colectiva (AC), con la diferencia de que mientras los primeros hablan de los MS como sujetos o actores de $\mathrm{AC}$, los segundos hablan de los MS como forma de AC.

Esta diferencia teórica sustancial ha sido casi totalmente ignorada, incluso por los más recientes promotores de una y otra vertiente, quienes han intentado presentarse, unos y otros, como parte de la misma escuela y compartiendo los mismos supuestos teóricos o, en sus términos, habrían llegado a consensos (Mcadam, Mccarthy, y Zald, 1999).

Sin embargo, el máximo exponente y precursor de la segunda vertiente referida, Charles Tilly, lo había expresado y expuesto claramente en su artículo elocuentemente (aunque de manera equivocada, como se verá) titulado -en su traducción al español- "Los movimientos sociales como agrupaciones históricamente específicas de actuaciones políticas" (Tilly, 1995). Dicho artículo nos servirá, pues, para ubicarnos en este campo polémico. 


\section{Hacia un concepto positivo y operativo de Movimiento Social, aplicable al estudio del Movimiento Estudiantil}

En el mencionado artículo, que nos parece de vital importancia por su inusual carácter polémico, Tilly presenta una gran ambigüedad en la definición, puesto que en el mismo habla del MS como "una forma compleja de acción", "un reto público ininterrumpido", "interacciones intermitentes", "medios comunes de acción política", "formas distintivas y específicas de acción social", "medio estándar de formular demandas", “agrupación de prácticas políticas estándar disponibles”, "agrupación de actuaciones que constituyen una campaña”, "medio disponible para contender”, “estrategia estándar de acción colectiva", y "medio estándar de librar las contiendas" (Tilly, 1995).

Tilly incurre en un error de niveles de abstracción, pues usa la misma expresión "movimiento social" (en singular o plural indiferentemente) para referirse a objetos diferenciables: las formas de prácticas, los conjuntos de dichas formas, las prácticas concretas que revisten tales formas, los conjuntos de dichas prácticas, y quienes se encuentran inmersos en dichas prácticas y las impulsan. Al parecer a todo lo llama movimiento social, excepto, claro, al conjunto humano inmerso en las prácticas, dada su grupofobia manifiesta.

Para sustentar dicha inconformidad con las visiones centradas en los grupos, Tilly se basa en su segunda definición aludida de movimientos sociales, en la cual los equipara con las campañas electorales y la política de grupos de interés, para señalar cómo ninguno de ellos consta de grupos. Es clave detenernos en dicho argumento por cuanto para nosotros es claro que estas otras dos formas remiten indefectiblemente a grupos que las usan: los partidos políticos y los grupos de interés, los cuales indudablemente son conjuntos humanos (grupos en un sentido amplio).

Ahora bien, ¿quién impulsa la forma "movimiento social"?, indudablemente un conjunto humano. El problema es que en los dos casos que usa de contraste existen palabras distintas para la forma y para quien la impulsa (la "política de grupo de interés" ha sido llamada lobby o cabildeo, la de los partidos campaña electoral), mientras que en el caso del MS no sucede lo mismo, por lo cual, para ser rigurosos dentro de las palabras a disposición, habría qué decir que un movimiento social despliega un movimiento social. 
Este problema de conceptualización proponemos resolverlo mediante la introducción de la expresión más genérica movilización de masas $(\mathrm{MM})$ como forma institucionalizada de práctica política ${ }^{6}$ en el capitalismo, específica de los movimientos sociales.

Dejando a un lado el asunto terminológico -determinante del asunto conceptual-, cabe rescatar el valioso esfuerzo teórico de Tilly, en el mismo artículo, por distinguir en el fenómeno MS sus niveles de existencia que a su vez implican niveles de abordaje. Dichos niveles serían:

1. La acción o interacción individual, por ejemplo, la exhibición de una pancarta rotulada o la firma de un pliego petitorio.

2. La secuencia de acciones o interacciones que conforman una actuación distinguible, por ejemplo, una manifestación o una declaración a periodistas.

3. La agrupación de actuaciones que constituye una campaña particular, (...)

4. El conjunto de campañas -pasadas, presentes, y futuras- que los activistas incorporan en su narrativa compartida del movimiento en un momento dado (...) 5 El repertorio de medios contenciosos disponibles a quienes hacen peticiones en un momento dado, independientemente de si realmente éstos se presentan en los movimientos sociales (...)

6. La serie de todos los repertorios que alguna vez han estado disponibles dentro de límites determinados en el tiempo y el espacio (Tilly, 1995: 19).

En primer lugar, Tilly descarta la utilidad del punto 4 , ya que al obedecer a las narrativas de los activistas, rompe con el continuum de la generalidad al involucrar teleologías omniabarcantes. Afirma que sus estudios se han concentrado en la relación entre los procesos micro (1 y 2) y los macro (5 y 6), en torno a innovaciones acumulativas y límites del repertorio, mientras que en el presente trabajo apunta al nivel 3: "Debido a que el surgimiento de una agrupación nueva -y hasta entonces inaceptable- de actuaciones, marcó la aparición definitiva del movimiento social como un medio disponible para contender" (Tilly, 1995: 20).

Partiendo de las precisiones terminológicas arriba anotadas, aparece como una evidencia que en su clasificación por niveles los tres primeros aluden a prácticas concretas de movilización-acciones, actuaciones, campañas-y los dos últimos a las formas que revisten o pueden revestir tales prácticas -repertorio y serie de repertorios-.

6 Forma entre formas. Las otras serían la confrontación armada, el cabildeo, la propaganda electoral y la política pública. 
Tomaremos pues los tres primeros -acción, actuación y campaña- (y también el cuarto, el conjunto de campañas incorporadas a una narrativa, pero reformulado) como útil clasificación de los niveles de existencia y abordaje de las prácticas de movilización de masas. Los dos últimos, referidos a las formas de las prácticas, se abordarán en un momento posterior de conceptualización, ubicados propiamente en el marco de la estructura táctica de la movilización de masas.

El cuarto punto aparece como elemento extraño por cuanto, al ubicarlo en las narrativas de los activistas, explícitamente lo excluye de su narrativa como sociólogo. Esto es más interesante de lo que parece, ya que allí reside la discusión sobre la historicidad de los movimientos.

Si el MS se ubica para Tilly al nivel de las campañas (nivel 3), y tales campañas son un reto público ininterrumpido, esto trae grandes consecuencias para nuestra pretensión de historizar el Movimiento Estudiantil. En efecto, habría que decir que en Colombia ha habido "movimientos estudiantiles", que, por ejemplo, hubo uno en 1971 y habría habido otro diferente en 2011. Así pues, el ME en Colombia no tendría existencia como uno y lo mismo, condición básica para su historicidad, y por tanto no tendría ni podría tener historia (ni siquiera en el nivel descriptivo).

Tilly no conoce pues sino una forma de historizar los "movimientos sociales" (en realidad la movilización de masas): habría una historia universal única e indiferenciada de los "movimientos sociales" (movilización de masas) que parte de Gran Bretaña en el siglo XVIII y se extiende por todo el mundo hasta nuestros días (no deja de ser elocuente el título de su último proyecto editorial: "Los movimientos sociales, 1768-2008. Desde sus orígenes hasta Facebook").

Discrepamos de tal planteamiento. En lo fundamental, porque adscribimos a una concepción de historia distinta a la que subyace a la propuesta de Tilly, la concepción materialista (Althusser, 1965). Simplemente diremos que, aunque coincidimos en afirmar que el ME en Colombia no tiene ni puede tener historia en sentido estricto, hay razones para plantear que tal movimiento sí tiene existencia histórica relativamente autónoma, que trasciende la individualidad concreta de las campañas (abarcando el nivel 4: los conjuntos de campañas), y que por tanto la pretensión de construir su historiografía descriptiva es académicamente legítima, más allá de las posibles narrativas de los activistas, pero también teniéndolas en cuenta como dato objetivo que hace parte de uno de sus elementos estructurantes. 
La existencia histórica de un MS, al igual que la de un partido político, no está ni puede estar dada por la continuidad o permanencia de sus "promotores", ni aún por el carácter ininterrumpido de sus prácticas. Es reconocido por ejemplo que un partido pueda ser considerado el mismo aun cuando sus miembros activos vayan cambiando con los años, y aun cuando no participe de campañas electorales sino cada determinado número de años -y aun cuando en algunas no participe en absoluto.

A un partido político se le considera el mismo partido por razones de continuidad y/o discontinuidad de algunos de sus elementos más característicos - estructurantes-, como por ejemplo su programa, sus símbolos, sus consignas, etc.

Así mismo nosotros planteamos que un MS puede ser considerado el mismo a partir de las líneas de continuidad o discontinuidad de sus elementos a través de la historia. Más aún, dado que tales líneas son la condición de enunciación de la existencia como tal del MS a través de la historia, ellas constituyen su definición descriptiva, como sigue:

Llamaremos Movimiento Social a las líneas de continuidad y discontinuidad que pueden establecerse, a través de campañas históricamente sucesivas, en la configuración de los elementos estructurantes de las prácticas de movilización de masas expresadas en dichas campañas.

Por lo demás, la presencia de tales líneas en cada campaña particular legitima la posibilidad de nombrar un movimiento social concreto en el presente al igual que en el pasado, por ejemplo hablar de $E l$ Movimiento Estudiantil colombiano en 1971 y el mismo en 2011, o incluso entre 1922 y 2013, ya que aún "por fuera" de las campañas se mantienen algunas de las líneas (afirmación que habrá que confrontar en la investigación).

Concluimos que un MS, y por tanto el Movimiento Estudiantil colombiano, puede tener historiografía coherente en ese nivel descriptivo de la historiografia, porque indudablemente, aunque un "ciclo de protesta estudiantil" -campaña- no necesariamente sea evolución y producto de uno anterior, sí puede -y generalmente lo hace- retomar elementos, aprender de errores, en últimas puede establecer y construir realmente -no sólo imaginariamente- una continuidad, no teleológica, aunque el discurso así lo exprese, pero sí efectiva y eficaz, y por tanto teórica y políticamente útil. 


\section{Categorías descriptivas para el estudio de los Movimientos sociales y del Movimiento}

\section{Estudiantil}

Se dijo que los MS son las líneas de los elementos de la movilización, vistas en campañas sucesivas. Los "observables" de las posibles investigaciones que se basen en dicho concepto, serían pues unos elementos presentes en unas campañas. La condición de tal observación es definir dichos elementos a ser observados.

Hasta el momento los estudiosos de los MS -tanto los que lo asocian a un grupo como los que lo confunden con la Movilización de Masas- han hablado de tres elementos esenciales que estarían presentes en todos ellos, a saber, Estructuras de Movilización, Estructura de Oportunidades Políticas y Procesos Enmarcadores. Esto se ha establecido abiertamente como un consenso en torno al cual parece no haber discusiones (Mcadam, Mccarthy, y Zald, 1999). Hemos supuesto que dicha actitud conciliadora y diplomática se debe a un interés por unificar la aún pequeña comunidad académica dedicada al estudio de MS.

Sin embargo, luego de una lectura atenta a algunos de sus textos fundamentales, para nosotros no está tan claro dicho consenso. En efecto, ¿todos los autores atribuyen a los tres elementos la misma importancia, el mismo índice de eficacia dentro del movimiento? La respuesta en el caso de todos ellos es un rotundo no. Pero en torno a las mencionadas diferencias teóricas tendremos necesariamente que cargar con las responsabilidades, dado el silencio diplomático del que hablamos.

Estos tres elementos han configurado en nuestra opinión el ámbito teórico desde el que los MS han sido abordados por las tres escuelas dominantes, cada una de las cuales se estructura a partir de tres autores fundantes:

1. Mancur Olson, precursor de la escuela de movilización de recursos, cuyos máximos exponentes son Mayer Zald, John D. McCarthy y Hans Peter Kriesi, y que prepondera el elemento Estructuras de Movilización;

2. Charles Tilly, precursor de la escuela del proceso político, cuyos máximos exponentes son el propio Tilly, Doug McAdam y Sidney Tarrow, y que preponderan el elemento Oportunidades Políticas;

3. Alain Touraine, precursor de la escuela de los nuevos movimientos sociales, cuyos máximos exponentes son el propio Touraine, Alberto Melucci y Klaus Offe, y que 
preponderan el elemento de Creación de Identidades, homólogo al elemento llamado, por los estadounidenses, Procesos Enmarcadores o Marcos Culturales.

El elemento que hasta el momento hemos delimitado a un nivel aceptable es el de Estructuras de Movilización, por considerar que, en primer lugar es el elemento en torno al cual se ha teorizado más en cuanto elemento estructurante. En segundo lugar porque nos parece uno de los más importantes de caracterizar. Al respecto, Archila nos dice: "El tema organizativo es el punto más agudo de debate y el mayor riesgo a la unidad, pues siendo la MANE un espacio de encuentro estudiantil y no una organización formal, centralizada y vertical como solían ser las del pasado, es difícil contar con una forma orgánica que garantice que todos sean escuchados" (Archila, 2012: 95).

McCarty concibe las estructuras de movilización (EM) como:

las formas consensuadas de llevar a cabo acciones colectivas, a los repertorios tácticos, a formas organizativas de movimientos sociales concretos y a repertorios modulares de los movimientos sociales. Quisiera hacer referencia también a los núcleos socioestructurales cotidianos de micromovilización (...). Es mi intención incluir todas las instituciones que, por lo general, se hallan en el límite de lo que se denomina 'sociedad civil', así como estructuras institucionales del Estado y del mundo de lo económico que puedan servir de contextos relacionales en la movilización de la protesta (Mcadam, Mccarthy, y Zald, 1999: 215).

Al concebir lo formal en su generalidad, incluye pues también los repertorios tácticos, por ser éstos formas de actuar del movimiento. Sin embargo, esta perspectiva ampliada de lo formal conduce fácilmente a difuminar los límites entre las categorías descriptivas de los elementos del movimiento social, ya que dentro de las formas podríamos también incluir las formas de pensar del movimiento, a saber, los llamados marcos culturales. Proponemos la expresión más precisa de Estructura de la Organización de la Movilización de Masas (EO).

En nuestra opinión las tácticas son un elemento cualitativamente muy diferente de la organización, y no sólo en sus lógicas de configuración, sino en su carácter mismo. Responden a preguntas políticas diferentes: lo segundo responde a qué se tiene y cómo está dis- 
puesto, las primeras responden más a la cuestión de las maneras posibles, viables y eficaces de usar -canalizar políticamente- esto que se tiene, tanto a corto, como a mediano y largo plazo, teniendo también en cuenta lo que tiene el actor contendor y cómo lo dispone. Así pues, los teóricos del elemento Estructuras de Movilización (McCarty es un representante) han subsumido dentro de tal categoría no sólo el elemento organizativo sino el elemento táctico, que en nuestra opinión es otro elemento estructurante de la movilización de masas.

Esta EO los diversos autores la han desglosado a su vez en sus elementos estructurantes, habiendo gran diferencia entre sus propuestas. Tarrow distingue entre organizaciones formales jerárquicas, organizaciones en el punto de contacto con los oponentes y estructuras conectivas entre las primeras y las segundas. Tres niveles internos en escala de formalidad (Tarrow, 1997). McCarty también sigue la lógica de la escala de formalidad, siendo más amplia que la de Tarrow. Comienza desde las familias y redes de amistades, pasando por las redes informales, los híbridos, los movimientos sociales organizados (MSOs), y los grupos intermedios (Mcadam, Mccarthy, y Zald, 1999).

Kriesi distingue entre MSOs (las organizaciones jerárquicas de Tarrow), Organizaciones de apoyo y Asociaciones del movimiento (Mcadam, Mccarthy, y Zald, 1999). Estas dos últimas, Tarrow las pierde de vista. Las primeras porque son externas y él sólo considera las internas, las segundas porque parten de una visión elitista (que Kriesi comparte con y retoma de McCarty) en la que la élite organizada (MSOs) organiza la base del movimiento concibiéndola como su clientela particular, mientras que para Tarrow las organizaciones de base tienen un alto grado de espontaneidad y autonomía. Mientras para aquellos el MS es otra forma de política de élites, para éste es política popular de desafío a las élites, en constante riesgo de cooptación por las mismas.

El hecho es que en la práctica se dan unas y otras, independientemente de que nuestras posturas políticas o morales nos hagan incómodo reconocerlo. Así pues, al no anclarnos en una perspectiva interpretativa previa (que sobredimensione lo "interno", o la élite, o la autonomía, etc), podemos incluir todos los elementos que consideremos efectivamente perceptibles y con efectos pertinentes sobre el movimiento.

Por esta senda que prioriza la amplitud descriptiva, Rucht aporta una novedosa clasificación, que rompe con el esquema rígido de diferenciación entre MS, Partidos políticos y Grupos de interés, con la cual coincidimos provisionalmente: 
Teniendo en cuenta la heterogeneidad de la estructura de los movimientos no puede resultar sorprendente que encontremos en su seno aquellas formas organizacionales que, analíticamente, habiamos separado de ellos, es decir, grupos de interés y partidos políticos (...). Si asumimos la posible coexistencia de grupos de base, grupos de interés y partidos en la infraestructura de un movimiento, debemos asumir también que, desde una perspectiva empírica, esto pueda tener consecuencias respecto del concepto de estructura del movimiento (Mcadam, Mccarthy, y Zald, 1999: 266).

Finalmente, nuestra perspectiva amplia y descriptiva nos permitirá avanzar en el camino de salida del eterno problema del origen social de los movimientos, expresado en estos autores como el problema de las redes informales. La solución a dicho problema proponemos buscarla en la práctica teórica de Mancur Olson, específicamente en su concepto de grupo latente (Olson, 2011).

Este concepto nos permite remitir a ese origen empírico amplio de las redes y organizaciones de base. Para nuestro caso de estudio, el grupo latente evidentemente será el Estudiantado, independientemente de que se le entienda como categoría de clase (Navia, 1997) o por el contrario como conjunto humano no clasista. No creemos por lo demás tener que argumentar mucho más para que se admita la simple afirmación de que el Movimiento Estudiantil encuentra su origen primario en el Estudiantado ese "grupo latente".

Así pues, inicial y provisionalmente, definiremos la Estructura Organizativa a partir de los siguientes elementos que ella contiene y combina, ordenados del más formal al más informal, o en otros términos, del más premeditadamente organizado al más espontáneo. Tales elementos son:

1. Las organizaciones encrucijada del movimiento, que cuestionan su pretendida autonomía, puesto que son organizaciones que por lo general existen antes de que emerja el movimiento y sus objetivos e intereses lo desbordan. Su interés en incidir sobre el movimiento puede ser más o menos decidido, pero cuando dicho interés es manifiesto su incidencia puede ser muy alta. En cierto sentido constituyen las conexiones del movimiento con entornos políticos más amplios, así como con conflictos que desbordan las problemáticas planteadas por el movimiento, planteando asuntos como el de las coaliciones y las alianzas, pero también los de la cooptación, la instrumentalización, la infiltración y el sabotaje, etc., lo cual nos remite al problema de 
si considerar o no a los agentes estatales -funcionarios públicos-, con presencia más o menos invisible en el movimiento, como un elemento más de su estructura formal.

2. La segunda triada de elementos constituyen propiamente el conjunto de formas organizativas propias del movimiento (a las que apunta Tarrow), las cuales surgen con él y para él, pero también suelen morir con él.

3. La tercera triada nos remite a los grupos originarios del movimiento, con lo cual pretendemos abarcar todo el espectro formal del movimiento, al menos en el rango en que sus nociones "empíricas" son proclives de ser percibidas y descritas.

En el cuadro anexo esbozamos un primer esfuerzo de operacionalización de ésta categoría en subcategorías, variables e indicadores, con el fin de potenciar su capacidad descriptiva. Las demás categorías deberán producirse en esfuerzos teóricos posteriores, en aras de completar herramientas suficientes que nos permitan organizar el trabajo de descripción de nuestro objeto como una captación específica de las informaciones que recojamos vía documental, periodística y de archivo y vía trabajos de campo.

\section{Conclusiones}

En el presente ensayo hemos sentado algunas bases teóricas y metodológicas fundamentales para emprender de manera colectiva la construcción de la historia del Movimiento Estudiantil en Colombia desde 1957. Partiendo de la pregunta por la verdadera dimensión histórica de la coyuntura de 2011, hemos demostrado la importancia de construir la memoria histórica en aras de contribuir al avance histórico presente. Pero no solo eso, sino además la necesidad del esfuerzo académico por analizar y comprender dicha historia. La etapa descriptiva surge aquí como la primera gran urgencia.

Tras desarrollar algunas discusiones epistémicas básicas, ha quedado definido que la historia descriptiva del ME hace parte de proyectos más amplios, como es la historia política de Colombia, única que podría dar cabida a análisis comprensivos de los fenómenos descritos, en una perspectiva politológica muy conectada con la Historia y la Sociología. Esta perspectiva politológica se retoma de la tradición académica de la acción colectiva y los movimientos sociales, por razones históricas que nos remontan a las discusiones provocadas por la época del "mayo parisino" (1967-1971) en todo el mundo. 
En las últimas dos partes del ensayo, hemos plasmado un esfuerzo que considerábamos indispensable y en mora de hacerse: la producción de un concepto operativo y claro de movimientos sociales, diferenciándolo del concepto de movilización de masas, en aras de darle estatuto teórico propio y derecho de existencia historiográfica a un movimiento social concreto, para nuestro caso el ME.

\section{Bibliografía}

ABADÍA, A. (2013). "Charlando sobre el ánimo de lucro en instituciones de educación superior y las movilizaciones estudiantiles en Chile y Colombia [Entrevista a Milton Vidal y Carlos Liévano]". En: Trans-pasando Fronteras, núm. 3, pp. 158-166. Cali: Universidad Icesi

ALTHUSSER, Louis. (1965). Hacia un concepto de historia. La pensé. (121).

ARCHILA, Mauricio. (2003). Idas y venidas, vueltas y revueltas. Protestas sociales en Colombia 1958- 1990. Bogotá, Colombia: CINEP.

(2012). El Movimiento Estudiantil en Colombia, una mirada histórica. Osal. Observatorio social de América Latina. (31) 71-104.

ARRUBLA, Mauricio (1978). Colombia Hoy. Bogotá, Colombia: Siglo veintiuno editores.

BOBBIO, Norberto; MATTEUCCI, Nicola y PASQUINO, Gianfranco. Diccionario de política. México DF, México: Siglo XXI.

BOYD, C. O. (1993). Phenomenology: The Method. En P. L. Munhall and C. O. Boyd (eds.). Nursing Research: A Qualitative Perspective. (pp. 99-132). New York, Estados Unidos de América: National League for Nursing.

GONZÁLEZ, Adriana. (2010). Acción colectiva , tropel y rutinas instaladas. En Universidad y coyuntura: una oportunidad para decir. (pp. 27-32). Medellín, Colombia: Instituto de Estudios Políticos, Universidad de Antioquia.

HOLSTEIN, J. A. y GUBRIUM, J. F. (1994). Phenomenology, Ethnomethodology, and Interpretative Practice. En N. K. Denzin and Y. S. Lincoln. Handbook of Qualitative Research. (pp. 262-272). California, Estados Unidos de América: Thousand Oaks. 
MCADAM, D. MCCARTHY, J. D., y ZALD, M. N. (1999). Movimientos sociales: perspectivas comparadas. Madrid, España: Ediciones Istmo.

MUÑOZ, Natalia y Andrea Hernandez (2013). "La MANE como mecanismo legítimo de representación estudiantil”. En: Trans-pasando Fronteras, núm. 3, pp. 5969. Cali: Universidad Icesi.

NAVIA, Lisandro. (1997). El estudiantado: nueva categoría social. Revista Universidad de Medellín. (65).

(1999). En la escuela: ¿está el prolegómeno al régimen político solidario?. Kabái, (4).

OLSON, Mancur. (1992). La lógica de la acción colectiva: Bienes públicos y teoría de grupos. Limusa S.A.

RIECHMANN, J. y FERNÁNDEZ, F. (1994). Redes que dan libertad: introducción a los nuevos movimientos sociales. Madrid, España: Paidós.

TARROW, Sidney. (1997). El poder en movimiento. Los movimientos sociales, la acción colectiva y la política. Madrid, España: Alianza Editorial.

TILLY, Charles. (2012). Los movimientos sociales 1768 - 2008. Desde sus orígenes a Facebook. Barcelona, España: Editorial Crítica, S. L.

(1995). Los movimientos sociales como agrupaciones históricamente específicas de actuaciones políticas. Sociológica. (28).

VAN MANNEN, M. (1990). Researching Lived Experience: Human Science for on Action Sensitive Pedagogy. Ontario, Londres: Althouse.

YIN, R. K. (1993). Applications of Case Study Research. Washington, D. C., Estados Unidos de América: Cosmos. 


\section{Linkografia}

Antígona (2011). "Sobre el Movimiento Estudiantil actual y su historia". En: Colectivo Antígona. Consultado el 10 de septiembre de 2014, desde http://goo.gl/nclkmW

\section{Anexos}

\section{ESTRUCTURA DE LA ORGANIZACIÓN}

\begin{tabular}{|c|c|c|}
\hline SUBCATEGORÍAS: & VARIABLES: & INDICADORES: \\
\hline \multicolumn{3}{|l|}{ 1. Organizaciones encrucijada } \\
\hline $\begin{array}{l}\text { a) Partidos y movimientos } \\
\text { políticos }\end{array}$ & $\begin{array}{l}\text { - Organizaciones de Izquierda } \\
\text { (legales e ilegales), agentes } \\
\text { estatales. }\end{array}$ & $\begin{array}{l}\text { - Intereses propios, presencia o ausencia (adscripción } \\
\text { o penetración), influencias táctica, influencias } \\
\text { organizativa, influencias cognoscitiva. }\end{array}$ \\
\hline b) Grupos de interés & $\begin{array}{l}\text { - Estamentos y gremios } \\
\text { escolares. }\end{array}$ & $\begin{array}{l}\text { - Intereses propios, recursos, nivel y forma de } \\
\text { incidencia, composición (cuantitativa y cualitativa). }\end{array}$ \\
\hline c) Oranizaciones de apoyo & - ONGs y sindicatos. & - Intereses propios, recursos, nivel y forma de incidencia. \\
\hline \multicolumn{3}{|l|}{$\begin{array}{l}\text { 2. Formas Organizativas del } \\
\text { Movimiento }\end{array}$} \\
\hline a) Organizaciones formales & $\begin{array}{l}\text { - Mesas, Federaciones, } \\
\text { Asociaciones, O. clandestinas, } \\
\text { amplias o programáticas. }\end{array}$ & $\begin{array}{l}\text { Nombre, cantidad, carácter, composición (cualitativa } \\
\text { y cuantitativa), duración, recursos, infraestructura, } \\
\text { alcance, actividades, símbolos, "estructura }\end{array}$ \\
\hline b) Estructuras conectivas & $\begin{array}{l}\text { - Oficinas y coordinadoras } \\
\text { estudiantiles. }\end{array}$ & $\begin{array}{l}\text { organizativa" interna, normas internas, divisiones y } \\
\text { pugnas, alianzas. }\end{array}$ \\
\hline $\begin{array}{l}\text { c) Asociaciones de } \\
\text { voluntarios }\end{array}$ & $\begin{array}{l}\text { - Comités y colectivos } \\
\text { estudiantiles. }\end{array}$ & \\
\hline \multicolumn{3}{|l|}{ 3. Grupos Originarios } \\
\hline a) Organizaciones de base & $\begin{array}{l}\text { - Organizaciones estudiantiles } \\
\text { de base }\end{array}$ & $\begin{array}{l}\text { - Nombre, cantidad, carácter, composición (cualitativa y } \\
\text { cuantitativa), duración. }\end{array}$ \\
\hline b) Redes informales & $\begin{array}{l}\text { - Relaciones de amistad y } \\
\text { sexuales }\end{array}$ & $\begin{array}{l}\text { - Presencia o ausencia (previa o posterior al } \\
\text { movimiento). }\end{array}$ \\
\hline c) Grupo latente & - Totalidad del estudiantado & $\begin{array}{l}\text { Comoposición interna (cuantitativas y cualitativa): } \\
\text { estrato, género, raza, edad, nivel educativo, servicio } \\
\text { de salud, empleo, duración de estudios, deserción. }\end{array}$ \\
\hline
\end{tabular}

Anexo 1. Las categorías que se proponen son las desarrolladas a través de varias décadas por la corriente estadounidense de los movimientos sociales, con algunas variaciones. Nuestra delimitación y operacionalización de la categoría Estructura Organizativa 
deberá ser ejemplo y punto de partida para ejercicios posteriores más completos, pero esperamos desde ya pueda ser útil a investigaciones en curso. Nuestro propósito ha sido contribuir a la motivación, difusión, ampliación y organización de procesos académicos individuales y colectivos dedicados al estudio de la historia de los movimientos sociales en Colombia ${ }^{7}$ (particularmente el ME que ha sido de los menos estudiados) como un aporte fundamental para la historia política de Colombia, una historia política que no tome por base los partidos políticos tradicionales (expresión política formal de las clases dominantes), sino las expresiones políticas de las clases subalternas y sus luchas, propósito más ambicioso, todavía pendiente, y al que deberíamos contribuir todos los científicos sociales comprometidos con nuestra realidad.

7 Expresión de lo cual es el Semillero de Movimientos Sociales que estamos próximos a lanzar en la Universidad de Antioquia. 